\section{Treatment or prevention?}

Disease prevention through health promotion has long been a tenet of osteopathic medicine, a philosophy practiced by enlightened physicians and patients. Otto F. Gursch, PhD, Professor Emeritus and Former Chairman of the Department of Microbiology at the Chicago College of Osteopathic Medicine, was fond of asking his students, "Is it better to build a fence at the edge of a cliff or a hospital at the bottom? Is it better to prevent the fall or to treat the fracture?" While the answer is obvious, it's not that simple. People do climb fences.

Recent reports on the use of aspirin for the primary prevention of myocardial infarction and of tretinoin to retard photoaging of the skin are examples of this prevention-treatment issue.

In January 1988 the Steering Committee of the Physicians' Health Study Research Group at Harvard Medical School and Brigham and Women's Hospital revealed their preliminary findings from a randomized, double-blind, placebo-controlled trial $^{1}$ studying the effects of aspirin on cardiovascular-related mortalities and whether beta carotene decreases the incidence of cancer.

In this trial, 22,071 male physicians were randomly assigned to four groups: aspirin and beta carotene; aspirin and placebo; placebo and beta carotene; or two placebos. The data indicated a significant beneficial effect on nonfatal and fatal myocardial infarction in the aspirin groups. The treatment group received buffered aspirin $(325 \mathrm{mg})$ on alternate days. These participants experienced a $47 \%$ reduction in the risk of total myocardial infarction. The results on the beta carotene component will not be available until 1990 .

The authors suggest that their data is consistent with aspirin's biological mechanisms. Furthermore, the complete inhibition of platelet aggregability has a clinically significant antithrombotic effect.
In a separate, unrelated report, topical tretinoin was found to improve the appearance of photoaged skin characterized as wrinkled, rough, leathery, and spotty. Over a four-month period in which tretinoin cream was applied daily to the skin of middleaged Caucasians, visual and histological improvements were noted. ${ }^{2}$

As exciting as these results are, caution is warranted. Efforts toward the prevention of coronary arteriosclerosis, the preeminent factor in acute myocardial infarction, should receive far more attention. It is not enough to take an aspirin every other day and disregard proper nutrition, exercise, and personal habits. Likewise, in lieu of any secondary treatment, photoaging prevention is best achieved by avoiding excessive ultraviolet rays and applying sun-blocking agents to protect against burning.

While major breakthroughs like these deserve our attention, they should bring a renewed commitment to prevention.

THOMAS WESLEY ALLEN, DO, FACOI

1. Preliminary report: Findings from the aspirin component of the ongoing Physicians' Health Study. New Engl J Med 1988;318:262-264.

2. Weiss JS, et al: Topical tretinoin improves photoaged skin. JAMA 1988;259:527-532. 
